\title{
Análise do alinhamento da estratégia de produção com a estratégia competitiva na indústria moveleira
}

\author{
Eliciane Maria da Silva \\ Universidade de São Paulo - Escola de Engenharia de São Carlos \\ Fernando César Almada Santos \\ Universidade de São Paulo - Escola de Engenharia de São Carlos
}

\begin{abstract}
Resumo
Este trabalho investiga o alinhamento das estratégias de produção com as estratégias competitivas adotadas por onze empresas moveleiras situadas no pólo industrial da região de Votuporanga - SP. Os questionários aplicados durante as entrevistas e as observações diretas no chão-de-fábrica foram as principais ferramentas escolhidas para coleta de dados. Os resultados da pesquisa de campo revelaram que a maioria das empresas produzia linhas variadas de móveis retilíneos com estilo tradicional. A comercialização ocorria em um mercado amplo com pouca ou nenhuma diferenciação, caracterizando a estratégia competitiva de menor custo. As prioridades competitivas da estratégia de produção eram predominantemente qualidade e custo. Observou-se a ausência de sistemas de medidas e de programas voltados para a gerência da qualidade, como de sistemas que objetivassem a redução do custo de produção. As preocupações com a competitividade ocorriam em curto prazo e não eram formalizadas em estratégias empresariais.
\end{abstract}

Palavras-chave

Estratégias de produção, estratégias competitivas, qualidade, custo, indústria moveleira.

\section{Analysis of the alignment of manufacturing and competitive strategies in the furniture industry}

\begin{abstract}
This paper investigates the alignment of manufacturing strategies with the competitive strategies of eleven companies located in the furniture cluster of Votuporanga - SP. The administration of questionnaires during interviews and direct observation in the shop floor were the main tools chosen for data collection. This research has revealed that the majority of the companies produced a varied number of straight line-like furniture of traditional style. The trading occurs in a broad market with little or null differentiation which is a clear indication of lower cost competitive strategy. The competitive priorities of manufacturing strategy were predominantly quality and cost. It has been noticed the lack of measurement systems and employment of training programmes towards quality management, as well as systems which aimed at the reduction of manufacturing costs. The concerns with competitiveness were only envisaged for the short run and were not formalized as company's strategies.
\end{abstract}




\section{INTRODUĈ̣̃O}

A razão desta pesquisa, voltada para empresas moveleiras de Votuporanga, decorre de fatores como o crescimento do número de empresas entre 1994 e 2001, da carência do setor em estudos e recursos em áreas de produção e da falência de algumas empresas em 2003.

No início da formação do pólo moveleiro em 1994, essa região possuía aproximadamente 75 empresas e empregava 3.159 trabalhadores (ABE e PAVAN, 1999). Em 2001 houve um aumento para 241 empresas e cerca de 8.083 funcionários (FUVEC, 2001). Porém, dados recentes apontam uma queda considerável num total de 85 empresas e 5.000 empregados (ABIMÓVEL, 2004).

Os estudos de Stipp (2002) e de Coutinho (2000) relataram progressos no setor, tais como: a inserção de projetos associativistas, a criação do Centro Tecnológico de Formação Profissional da Madeira e do Mobiliário - CEMAD - e investimentos em máquinas e equipamentos, possibilitando a modernização das fábricas. No entanto, o MCT (1993) revela que a indústria moveleira apresenta problemas de gerenciamento e de aplicação de recursos, tais como: a elevada verticalização e heterogeneidade nas gerações de equipamentos e lay-outs adotados nas fábricas, havendo divisão de trabalho entre várias linhas de produção que coexistem lado a lado.

Atualmente, a produção de Votuporanga é totalmente consumida pelo mercado interno e as empresas estão perdendo a competitividade. Os resultados deste trabalho mostraram ausência de planejamento e avaliação do desempenho da produção em várias áreas. Além disso, constatouse a necessidade de uma reestruturação e o interesse de alguns empresários em desenvolver projetos que centralizem suas vendas para o mercado externo.

$\mathrm{O}$ presente trabalho tem a finalidade de investigar o alinhamento das estratégias de produção com as estratégias competitivas em onze empresas moveleiras. A revisão da literatura abrange trabalhos como os de Wheelwright e Hayes (1985), Swamidas e Newell (1987), Pires (1994), Mills, Platts e Gregory (1995), Hill (1997) e Slack et al. (1999). Nessas obras, afirmase a importância de a estratégia de produção estar alinhada à(s) estratégia(s) competitiva(s) das empresas e frisa-se, também, a relevância de planejar as atividades da gestão da produção.

\section{ESTRATÉGIAS COMPETITIVAS E ESTRATÉGIAS DE PRODUC̄ÃO}

No âmbito empresarial, a estratégia está relacionada à arte de utilizar adequadamente os recursos físicos, financeiros e humanos, tendo em vista a minimização dos problemas e a maximização das oportunidades do ambiente da empresa (OLIVEIRA, 1991).

Porter (1985) afirma que as empresas devem buscar um posicionamento adequado para obter vantagem competitiva sobre os concorrentes. Esse posicionamento é obtido por três estratégias genéricas: liderança no custo total, diferenciação e enfoque.

Nesse trabalho, Porter (1985) diz que essas três estratégias diferem em algumas dimensões, tais como a exigência de diferentes recursos, habilidades, arranjos organizacionais e procedimentos de controle. Nota-se que tais dimensões abrangem áreas relativas à produção.

A liderança no custo consiste em atingir vantagem competitiva por meio da transformação da empresa com a produção concentrada em menor custo do produto, o que pode proporcionar a prática de menores preços. Algumas das várias formas de se alcançar essa estratégia são: simplificar a fabricação de produtos, investimento de monta em equipamento atualizado, fixação agressiva de preço e prejuízos iniciais para consolidar uma grande parcela de mercado e acesso preferencial à matériaprima.

\section{- studos revelam que a indústria de móveis - brasileira apresenta elevada verticalização, heterogeneidade nas gerações de equipamentos} e lay-outs adotados nas fábricas.
Já a estratégia de diferenciação resume-se em diferenciar o produto ou serviço oferecido pela empresa, criando algo que seja considerado único perante os concorrentes. Os métodos mais comuns para assumir essa estratégia são: projeto ou imagem da marca, qualidade do produto, durabilidade do produto, assistência técnica ou estilo do projeto.

A estratégia de enfoque se caracteriza pela centralização em um determinado grupo comprador, ou em um segmento de linha de produtos, ou em um mercado geográfico. Essa estratégia possui a premissa de atender a um alvo estreito e mais efetivo, ao contrário da forma mais ampla adotada pela concorrência. Conseqüentemente, a empresa atinge a diferenciação por satisfazer 
melhor as necessidades do seu alvo particular, ou custos mais baixos na obtenção desse alvo, ou ambos.

Os estudos e fundamentos da estratégia de produção foram introduzidos no final da década de 1960, mas se observa que o aperfeiçoamento e a implementação de técnicas ainda não se consolidaram (MILLS, PLATTS \& GREGORY, 1995; ALVES FILHO \& VANALLE, 1998). Segundo Voss (1995), esse assunto é discutido de forma muito ampla e sua aplicação não se tornou muito clara em razão das diferentes considerações e enfoques emergentes.

Skinner (1969) descreve alguns padrões comuns para mensurar o desempenho da produção, tais como ciclos menores de entrega do produto, produto com qualidade e confiabilidade, cumprimento da promessa de entrega, habilidade para produzir novos produtos rapidamente, flexibilidade para ajustar mudanças no volume e custos baixos.

Em meados da década de 1980, Hayes e Wheelwright (1984) introduzem o termo "prioridades competitivas". Estes autores delineiam quatro dimensões competitivas básicas: preço, qualidade, confiabilidade, e flexibilidade.

Hill (1997) desenvolve e sintetiza um grupo de critérios vencedores de produção:

- Preço, que está muito associado ao baixo custo de produção;

- Produto com qualidade, em especial suas dimensões em conformidade com especificações e confiabilidade;

- Entrega rápida e confiável, o que exige habilidade para responder ao aumento da demanda.
Wheelwright e Hayes (1985) dizem que a função "produção" pode oferecer contribuição ao sucesso de uma companhia e prover uma fonte principal de vantagem competitiva. A produção é freqüentemente composta de fatores que estão em diferentes níveis de desenvolvimento e que determinam o nível global da operação quando há um equilíbrio entre eles. Esses fatores também são conhecidos e classificados em duas categorias de decisão (Figura 1): a) as decisões estruturais, que são definidas pelas áreas de instalações industriais, capacidade produtiva, tecnologia e integração vertical; e b) as decisões infra-estruturais, que são definidas pelas áreas de recursos humanos, gerência da qualidade, organização e planejamento e controle da produção (PIRES, 1994).

Slack et al. (1999) afirmam que todas as macrooperações da organização são constituídas de uma hierarquia de microoperações. Fine e Hax (1985) argumentam que a estratégia de produção tanto é influenciada como influencia a estratégia corporativa. Assim, a ligação é de mão dupla.

Para Slack et al. (1999), o conteúdo de uma estratégia de produção é constituído por três fatores:

- Definição das prioridades competitivas mais significativas nas operações;

- Decisões estratégicas que determinam a estrutura da produção;

- Decisões estratégicas que determinam sua infra-estrutura. Moreira (2001) destaca que não existe uma forma

Figura 1: Síntese da hierarquia e do conteúdo das estratégias competitivas e de produção.

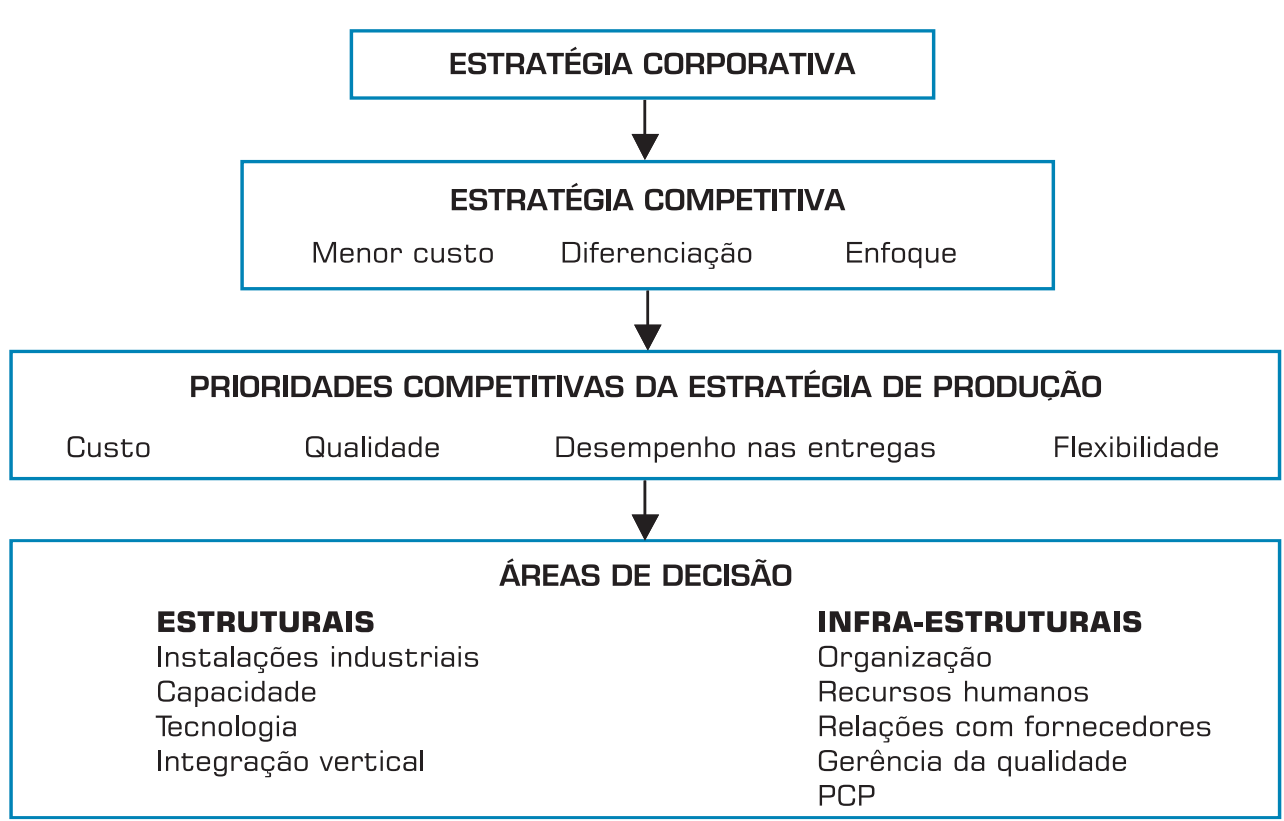

Fonte: Adaptado de Pires (1994) 
padronizada de um modelo de planejamento estratégico. Segundo este autor, alguns componentes fundamentais devem compor o planejamento estratégico de produção: tecnologia do produto, tecnologia do processo, capacidade de instalações, localização das instalações, recursos humanos e suprimentos. Afirma-se que algumas funções constituídas por decisões estratégicas na organização são derivadas da estratégia de produção da empresa e, quase sempre, as suas respostas dependem da aprovação da alta gerência. Por exemplo, as funções de planejamento da capacidade, a localização de instalações e os projetos do produto e do processo.

Barros Neto et al. (1999) defendem a necessidade da realização de trabalhos empíricos mais específicos, apresentando um modelo de formulação de estratégias de produção para pequenas empresas do ramo de construção civil que envolve as seguintes etapas:

- Reunião de apresentação, em que se mostra o processo de formulação detalhando cada uma de suas partes, os critérios competitivos e as categorias de decisão utilizadas;

- Diagnóstico estratégico da produção;

- Definição dos objetivos da empresa e conhecimento dos clientes e concorrentes;

- Desdobramento dos objetivos e desenvolvimento dos planos de ação;

- Cronograma e implementação.

\section{METODOLOGIA DE PESQUISA}

A metodologia de pesquisa utilizada no estudo de casos foi dividida em duas etapas. A primeira iniciou-se com uma ampla revisão bibliográfica referente à indústria de móveis internacional e nacional. A segunda constituiu-se de uma pesquisa de campo por meio de um estudo multicasos in loco em onze empresas na região de Votuporanga-SP.

Adotou-se uma pesquisa descritiva exploratória, a qual busca familiarizar-se ou identificar-se com os conceitos iniciais sobre um tópico, descobrindo novas possibilidades e dimensões da população de interesse (FREITAS et al., 2000).

Os instrumentos escolhidos para coleta de dados foram questionários aplicados por meio de entrevistas e observações diretas no chão-de-fábrica.

Foram entrevistados dois tipos de profissionais: o diretor ou gerente geral e o engenheiro ou responsável pela produção, os quais podem definir, respectivamente, a estratégia competitiva global e as prioridades competitivas da produção. As 20 questões aplicadas à alta administração e as 12 aplicadas à gestão da produção foram assim agrupadas:

- Estratégias competitivas adotadas pelas empresas;
- Principais matérias-primas e formas de comercialização utilizadas;

- Tecnologia, tipo de automação, integração vertical e relação com fornecedores;

- Projeto do produto, organização, planejamento e controle da produção e indicadores de desempenho da produção;

- Sistemas de controle de qualidade.

Conforme relatório de empresas cadastradas, fornecido pelo FUVEC (2001), o noroeste paulista, em que se insere a região de Votuporanga, é composto por 303 empresas moveleiras. Destas, foram selecionadas para análise apenas aquelas especializadas na fabricação de móveis de madeira para uso residencial. Assim, o universo de firmas sob investigação ficou reduzido a 111 empresas. Optou-se por selecionar uma amostra de 11 empresas, baseada em uma metodologia de casos múltiplos de caráter exploratório. O uso de casos múltiplos objetiva proporcionar evidências de empresas inseridas em diferentes contextos, com o intuito de tornar a pesquisa mais robusta (YIN, 1994).

O conceito utilizado para a escolha das 11 empresas entrevistadas foi o de amostra probabilística aleatória simples. A principal característica desse processo é o fato de todos os elementos da população terem a mesma chance de ser escolhidos por meio de um sorteio em uma tabela de números aleatórios (MARCONI \& LAKATOS, 2002). Após o sorteio, convidadas via telefone, essas 11 empresas aceitaram participar da pesquisa. O estudo de casos foi realizado durante o segundo semestre de 2002, entre os meses de setembro e dezembro.

\section{HISTÓRICO DA PRODUC̣ÃO DE MÓVEIS NO BRASIL}

Segundo Santi (2000), a industrialização do mobiliário brasileiro teve suas origens em 1875 pela produção de artesãos, sendo a maioria italiana. Essas empresas se caracterizavam pela estrutura familiar, com pequenas oficinas de produção artesanal, geradas pelo grande aumento do fluxo imigratório no final do século XIX e início do século XX.

Nos primórdios, os móveis eram produzidos com madeira maciça e quase sempre sob medida, encomendados por consumidores brasileiros. A partir de 1936, houve um desenvolvimento significativo das empresas moveleiras no Brasil. Um estudo de Ferreira (2001) diz que foi somente na década de 1950 que se consolidaram os principais pólos moveleiros no Brasil.

Atualmente, esse setor apresenta-se geograficamente disperso por todo o território nacional, concentrando-se, principalmente, nas regiões Centro-Sul. As indústrias se caracterizam pela organização em pólos regionais. Os 
grandes produtores nacionais são: Grande São Paulo (SP), Bento Gonçalves (RS), São Bento do Sul (SC), Arapongas (PR), Ubá (MG), Mirassol (SP), Votuporanga (SP) e Linhares (ES).

Embora a Associação Brasileira de Móveis ABIMÓVEL - tenha registrado um total de 13.500 empresas moveleiras, uma reportagem do jornal Gazeta Mercantil afirma que existem atualmente cerca de $50 \mathrm{mil}$ empresas em todo o País cadastradas em juntas comerciais como fabricantes de móveis. Mas, é provável que haja, pelo menos, mais 20 mil empresas informais em atuação no mercado interno. Desse total de 70 mil, aproximadamente $93 \%$ seriam microempresas (ABIMOVEL, 2001; GAZETA MERCANTIL, 2001).
Estado. Essa área era uma rica mata nativa que possuía várias espécies de madeira de lei. Isto resultou na comercialização da madeira nas décadas de 40 e 50, fase que recebeu o nome de "ciclo da madeira". O ciclo da madeira originou-se com a derrubada das árvores que constituíam a mata nativa para o preparo da terra e desenvolvimento da agricultura, sendo o produto principal o café. As primeiras serrarias e, conseqüentemente, a confecção de todo tipo de artefato de madeira, dentre eles mobiliário de casa, móveis para escritórios, instalações para igrejas, escolas, clubes, restaurantes, campo, indústrias e comércio em geral, surgiram como subproduto da atividade agrícola (STIPP, 2002).

Segundo Abe e Pavan (1999), a empresa de Móveis e Estofados A. B. Pereira, instalada em 1962, foi a primeira indústria de produção em série em Votuporanga. Essa indústria continua até hoje produzindo sofás e poltronas.

De acordo com a FUVEC (2001), a região de Votuporanga tem aproximadamente 241 empresas moveleiras, sendo que 107 estão no muni-

O faturamento da indústria de móveis, no ano de 2000, totalizou em $\mathrm{R} \$ 8,8$ bilhões. Cerca de $88 \%$ da produção doméstica é proveniente dos Estados de São Paulo, Rio Grande do Sul e Santa Catarina. Em 1999, este setor empregou 781.823 pessoas (ABIMOVEL, 2001).

$\mathrm{O}$ consumo nacional é suprido quase integralmente pela produção doméstica e as importações têm participação muito pequena. As principais regiões consumidoras são Sul e Sudeste, destacando-se São Paulo e região do ABC, Belo Horizonte, Curitiba, Porto Alegre, Rio de Janeiro e Brasília (GORINI, 2000, p.36). Em 2002 as exportações totalizaram US\$582.483.487,00 e em 2003, US\$ 661.556.905,00. Os Estados que mais exportaram naquele ano foram: Santa Catarina $(50,00 \%)$, Rio Grande do Sul (27,31\%), Paraná (9,13\%), São Paulo $(6,02 \%)$ e Bahia (4,3\%) (ABIMÓVEL, 2004).

A maior parcela das exportações é constituída por móveis de madeira $(60 \%)$ e a principal categoria é representada pelos móveis residenciais, incluindo cozinhas e dormitórios. Em seguida destacam-se assentos, cadeiras (inclusive giratórias) e móveis de metal e plástico (ABIMÓVEL, 2002).

\section{EVOLUC̣̃̃O DO PÓLO MOVELEIRO DE VOTUPORANGA}

A cidade de Votuporanga, fundada em 1937, está situada a $520 \mathrm{~km}$ da capital São Paulo, no noroeste do cípio de Votuporanga.

\section{ESTRATÉGIAS COMPETITIVAS E ESTRATÉGIAS DE PRODUC̣ÃO ADOTADAS}

As empresas I e $\mathrm{H}$, consideradas microempresas, com uma área fabril de $802 \mathrm{~m}^{2}$ e $1.348 \mathrm{~m}^{2}$, respectivamente, possuíam entre 7 e 19 funcionários e um faturamento anual de aproximadamente $\mathrm{R} \$ 700.000,00$ e $\mathrm{R} \$$ 1.500.000,00. As empresas A, C, D, F, e J, classificadas como pequenas, tinham área fabril entre $1.200 \mathrm{~m}^{2} \mathrm{e}$ $3.300 \mathrm{~m}^{2}$, empregavam de 32 a 50 funcionários e tinham um faturamento anual de $\mathrm{R} \$ 1.200 .000,00$ a $\mathrm{R} \$$ 3.609.783,40. Já as empresas B, E, G e K, consideradas de porte médio, possuíam uma área fabril entre $9.250 \mathrm{~m}^{2}$ e $11.800 \mathrm{~m}^{2}$, o número de funcionários era de 110 a 277 e, ainda, apresentavam faturamento anual de $\mathrm{R} \$ 9.000 .000,00$ a R $25.592 .319,12$ (Tabela 1).

Ressalta-se que a empresa B possui um faturamento elevado em razão de ser de porte médio e de possuir apenas a linha de produto de estofados, ocorrendo uma produção em maior escala.

A estratégia competitiva de menor custo foi predominante nessas empresas e as prioridades competitivas da estratégia de produção de maior prática e por ordenação eram a qualidade do produto final (8 incidências) e o custo de produção (6 incidências) (Tabela 1). Essa afirmação decorre de estudos sobre as questões estruturais 
e infra-estruturais, discutidas nos próximos tópicos desse artigo.

De acordo com o SEBRAE (2005), o porte da empresa foi baseado na classificação por número de funcionários: microempresa de 0 a 19; pequena empresa, de 20 a 99; média empresa de 100 a 499; e grande empresa, acima de 500 .

Das empresas pesquisadas quatro comercializavam dormitórios, ou seja, camas, guarda-roupas e cômodas; três fabricavam somente assentos (sofás); as outras quatro produziam dormitórios, assentos e mesas (Tabela 2).

Percebeu-se que a diferença no porte das empresas não se refletia no tipo e estilo dos móveis produzidos, bem como na matéria-prima utilizada.

A maior parte dos móveis era retilínea, isto é, móveis lisos, com desenhos simples e linhas retas (Tabela 2). Apenas três fabricam, unicamente, detalhes torneados de acabamento. Prevalecia o estilo tradicional dos móveis.

As principais matérias-primas utilizadas eram o painel de medium density fiber - MDF, a madeira nativa, a madeira reflorestada de pinus e o painel compensado (Tabela 2).

Duas formas de comercialização de produtos, por ordem de prioridade, foram citadas pelas empresas (Tabela 2):

- Venda direta a pequenos e médios varejistas da região e outros Estados (10 empresas);

- Venda a clientes da própria cidade e região (5 empresas).

\section{DECISÕES ESTRUTURAIS E INFRA- ESTRUTURAIS DA PRODUC̄ÃO}

Com base na coleta dos dados avaliou-se a combinação das prioridades competitivas com as áreas de decisões estruturais e infra-estruturais.

$\mathrm{Na}$ área de tecnologia, todas as empresas indicaram possuir algum sistema de informática. As empresas D, E, $\mathrm{F}, \mathrm{H}$, I e J disseram ter sistema CAD/CAM para desenvolvimento de projeto, ao contrário das empresas A, B, $\mathrm{C}$, G e K que não o possuíam. Das empresas que utilizam o sistema CAD constatou-se que a principal razão para usá-lo é melhorar a qualidade do projeto, permitindo ao projetista uma análise de engenharia mais completa e um número maior de alternativas de projeto. Ainda que essas empresas afirmassem ter o sistema CAM, não foi constatada a sua utilização (Tabela 3 ).

$\mathrm{O}$ processo fabril moveleiro apresentava-se com uma grande diversidade de máquinas e equipamentos, assim como também existia uma disparidade muito grande quanto ao grau de modernização tecnológica. Em geral as empresas utilizavam na linha de produção, conjuntamente, equipamentos obsoletos e modernos (Figura 3). A maior parte das máquinas observadas nas empresas era do tipo automação fixa, que provêm de alta taxa de produção e pouca flexibilidade, caracterizando um processo de produção com pouca diversificação (móveis

Tabela 1: Características gerais, estratégias competitivas e prioridades competitivas.

\begin{tabular}{|c|c|c|c|c|c|c|}
\hline \multicolumn{2}{|c|}{$\begin{array}{l}\text { EMPRESA E } \\
\text { ESTRATÉGIA } \\
\text { COMPETITIVA }\end{array}$} & \multirow{2}{*}{$\begin{array}{c}\text { PRIORIDADES } \\
\text { COMPETITIVAS } \\
\text { DE PRODUÇÃO } \\
Q^{1}, Q^{2}\end{array}$} & \multirow{2}{*}{$\begin{array}{c}\text { DIMENSÃO DA } \\
\text { ÁREA FABRIL } \\
\text { (MIL M } \text { M }^{2}\end{array}$} & \multicolumn{2}{|c|}{$\begin{array}{l}\text { PORTE DA } \\
\text { EMPRESA E N }{ }^{\circ} \text { DE } \\
\text { FUNGIONÁRIOS }\end{array}$} & $\begin{array}{l}\text { FATURAMENTO BRUTO } \\
\text { ANUAL EM 2001 } \\
\text { (RS MILHÕES) }\end{array}$ \\
\hline A & $\mathrm{MC}$ & & & Pequena & 50 & $\mathrm{R} \$ \quad 1.200 .000,00$ \\
\hline$B$ & MC & $Q^{1}, C$ & 9.439 & Média & 277 & $\mathrm{R} \$ 25.592 .319,12$ \\
\hline C & MC & $Q^{1}, C$ & 1.200 & Pequena & 35 & $\mathrm{R} \$ \quad 1.200 .000,00$ \\
\hline $\mathrm{D}$ & MC & $Q^{1}, C$ & 3.000 & Pequena & 32 & $\mathrm{R} \$ \quad 3.609 .783,40$ \\
\hline$E$ & MC & $Q^{1}, Q^{2}$ & 9.250 & Média & 110 & $R \$ 9.000 .000,00$ \\
\hline $\mathrm{F}$ & $\mathrm{MC}$ & C, D & 1.200 & Pequena & 38 & $\mathrm{R} \$ \quad 1.500 .000,00$ \\
\hline G & $\mathrm{MC}$ & $Q^{1}, F$ & 9.250 & Média & 138 & $\mathrm{R} \$ \quad 9.000 .000,00$ \\
\hline $\mathrm{H}$ & MC & $F, C$ & 1.348 & Micro & 19 & $\mathrm{R} \$ \quad 1.500 .000,00$ \\
\hline I & MC & $Q^{1}, C$ & 802 & Micro & 7 & $700.000,00$ \\
\hline$J$ & $\mathrm{MC}$ & $\mathrm{C}, \mathrm{Q}^{1}$ & 3.300 & Pequena & 40 & $\mathrm{R} \$ 2.000 .000,00$ \\
\hline K & MC & $Q^{1}, C$ & 11.800 & Média & 253 & $\mathrm{R} \$ 12.135 .526,37$ \\
\hline
\end{tabular}

Nota: MC: estratégia competitiva de Menor Custo

$Q^{1}$ : Qualidade do produto final

$Q^{2}$ : Qualidade conforme especificações técnicas do projeto

C: Custo

F: Flexibilidade 
populares e de linhas retas). Existia, porém, um número menor de máquinas com automação programável responsáveis pela produção de lotes compostos de médios e pequenos volumes (Tabela 3 ).
As máquinas de automação fixa possuem apenas uma função e não são programadas por computadores. Essas máquinas são preparadas fisicamente a cada mudança de lote de produtos, tais como: furadeira, esquadrejadeira,

Tabela 2: Linhas, classificação e estilos dos móveis; matéria-prima e comercialização.

\begin{tabular}{|c|c|c|c|c|c|}
\hline 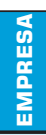 & $\begin{array}{l}\text { LINHAS } \\
\text { DE } \\
\text { PRODUTO }\end{array}$ & $\begin{array}{l}\text { CLASSIFI- } \\
\text { GAÇÃO DO } \\
\text { MÓVEL. }\end{array}$ & $\begin{array}{l}\text { ESTILOS } \\
\text { DOS } \\
\text { MóvEIS }\end{array}$ & $\begin{array}{l}\text { PRINGIPAL } \\
\text { MATÉERIA- } \\
\text { PRIMA }\end{array}$ & $\begin{array}{c}\text { FORMA DE } \\
\text { GOMERGIALIZAÇÃO }\end{array}$ \\
\hline A & Dormitórios & $\begin{array}{l}\text { Retilíneo com } \\
\text { detalhes } \\
\text { torneados }\end{array}$ & Tradicional & $\begin{array}{l}\text { Cerejeira, } \\
\text { marupá, pinus, } \\
\text { MDF e } \\
\text { Compensado }\end{array}$ & $\begin{array}{l}\text { Venda direta para pequenos e médios } \\
\text { varejistas da própria região e de } \\
\text { outros Estados. }\end{array}$ \\
\hline $\mathrm{B}$ & Assentos & Retilíneo & $\begin{array}{l}\text { Tradicional e } \\
\text { moderno }\end{array}$ & Pinus e pinho & $\begin{array}{l}\text { Venda direta para pequenos e médios } \\
\text { varejistas da própria região e de outros } \\
\text { Estados. }\end{array}$ \\
\hline C & Assentos & Retilíneo & Tradicional & Cedrilho e MDF & $\begin{array}{l}\text { Venda direta para pequenos e médios } \\
\text { varejistas da própria região, de outros } \\
\text { Estados e para clientes da própria cidade. }\end{array}$ \\
\hline $\mathrm{D}$ & Dormitórios & Retilíneo & $\begin{array}{l}\text { Tradicional e } \\
\text { moderno }\end{array}$ & MDF & $\begin{array}{l}\text { Venda direta para pequenos e médios } \\
\text { varejistas da própria região, de outros } \\
\text { Estados, da própria cidade e para } \\
\text { varejistas de outros países. }\end{array}$ \\
\hline$E$ & Dormitórios & Retilíneo & $\begin{array}{l}\text { Tradicional e } \\
\text { moderno }\end{array}$ & $\begin{array}{l}\text { MDF, } \\
\text { aglomerado e } \\
\text { compensado }\end{array}$ & $\begin{array}{l}\text { Venda direta para pequenos e médios } \\
\text { varejistas da própria região e de } \\
\text { outros Estados. }\end{array}$ \\
\hline $\mathrm{F}$ & $\begin{array}{l}\text { Dormitórios e } \\
\text { mesas }\end{array}$ & Retilíneo & $\begin{array}{c}\text { Tradicional e } \\
\text { contemporâneo }\end{array}$ & Angelim & $\begin{array}{l}\text { Venda direta para pequenos e médios } \\
\text { varejistas da própria região, de outros } \\
\text { Estados e da própria cidade. }\end{array}$ \\
\hline$G$ & Dormitórios & Retilíneo & Tradicional & $\begin{array}{l}\text { Tauari, ibirema, } \\
\text { angelim, pinus e } \\
\text { MDF }\end{array}$ & $\begin{array}{l}\text { Venda direta para pequenos e médios } \\
\text { varejistas da própria região e de } \\
\text { outros Estados. }\end{array}$ \\
\hline $\mathrm{H}$ & Assentos & $\begin{array}{l}\text { Retilíneo com } \\
\text { detalhes } \\
\text { torneados }\end{array}$ & $\begin{array}{l}\text { Tradicional e } \\
\text { moderno }\end{array}$ & $\begin{array}{l}\text { Pinus, eucalipto } \\
\text { e compensado }\end{array}$ & $\begin{array}{l}\text { Venda direta para pequenos e médios } \\
\text { varejistas da própria região e de } \\
\text { outros Estados. }\end{array}$ \\
\hline I & $\begin{array}{l}\text { Dormitórios, } \\
\text { armários, } \\
\text { estantes, mesas, } \\
\text { banheiros, } \\
\text { cozinhas e infantis }\end{array}$ & Retilíneo & $\begin{array}{l}\text { Tradicional e } \\
\text { moderno }\end{array}$ & MDF & $\begin{array}{l}\text { Venda direta para clientes da própria } \\
\text { cidade e região e para Grande São Paulo. }\end{array}$ \\
\hline J & $\begin{array}{l}\text { Assentos, } \\
\text { dormitórios e } \\
\text { mesas }\end{array}$ & Retilíneo & Tradicional & $\begin{array}{l}\text { Marupá } \\
\text { e jarapá }\end{array}$ & $\begin{array}{l}\text { Venda direta para pequenos e médios } \\
\text { varejistas da própria região, de outros } \\
\text { Estados e da própria cidade. }\end{array}$ \\
\hline $\mathrm{K}$ & $\begin{array}{l}\text { Assento, } \\
\text { dormitórios e } \\
\text { mesas }\end{array}$ & $\begin{array}{l}\text { Retilíneo com } \\
\text { detalhes } \\
\text { torneados }\end{array}$ & $\begin{array}{l}\text { Tradicional e } \\
\text { moderno }\end{array}$ & Jarapá & $\begin{array}{l}\text { Venda direta para pequenos e médios } \\
\text { varejistas da própria região, de outros } \\
\text { Estados e da própria cidade. }\end{array}$ \\
\hline
\end{tabular}


Tabela 3: Tecnologia, automação, integração vertical e relação com fornecedores.

\begin{tabular}{|c|c|c|c|}
\hline $\begin{array}{l}\text { PORTE DAS } \\
\text { EMPRESAS }\end{array}$ & $\begin{array}{l}\text { TECNOLOGIA / } \\
\text { TIPO DE AUTOMAÇÃO }\end{array}$ & $\begin{array}{l}\text { INTEGRAÇÃO } \\
\text { VERTIGAL }\end{array}$ & $\begin{array}{l}\text { RELAÇÃO COM OS } \\
\text { FORNECEDORES }\end{array}$ \\
\hline A - Pequena & $\begin{array}{l}6 \text { máquinas com automação } \\
\text { fixa e } 4 \text { máquinas com } \\
\text { automação programável }\end{array}$ & $\begin{array}{c}\text { Produção } 100 \% \text { verticalizada; } \\
\text { atividades indiretas terceirizadas: } \\
\text { manutenção de máquinas } \\
\text { e informática }\end{array}$ & $\begin{array}{c}\text { Relações com múltiplos } \\
\text { fornecedores baseadas no } \\
\text { baixo preço e qualidade da } \\
\text { matéria-prima }\end{array}$ \\
\hline B - Média & $\begin{array}{l}7 \text { máquinas com automação } \\
\text { fixa e ocorrência de estágio } \\
\text { manual em } 50 \% \text { do processo }\end{array}$ & $\begin{array}{l}\text { Produção } 100 \% \text { verticalizada; } \\
\text { atividades indiretas terceirizadas: } \\
\text { informática e transporte }\end{array}$ & $\begin{array}{l}\text { Relações com múltiplos fornece- } \\
\text { dores baseadas no baixo preço } \\
\text { e qualidade da matéria-prima }\end{array}$ \\
\hline C - Pequena & $\begin{array}{l}5 \text { máquinas com automação } \\
\text { fixa; e ocorrência de estágio } \\
\text { manual em } 50 \% \text { do processo }\end{array}$ & $\begin{array}{l}\text { 2\% da produção era terceirizada; } \\
\text { atividades indiretas terceirizadas: } \\
\text { manutenção de máquinas, } \\
\text { informática, transporte, } \\
\text { contabilidade e depto. pessoal }\end{array}$ & $\begin{array}{l}\text { Relações com múltiplos fornece- } \\
\text { dores baseadas no baixo preço } \\
\text { e qualidade da matéria-prima }\end{array}$ \\
\hline D - Pequena & $\begin{array}{l}\text { CAD/CAM, } 6 \text { máquinas com } \\
\text { automação fixa e } 4 \text { máquinas } \\
\text { com automação programável }\end{array}$ & $\begin{array}{c}\text { Produção e outras áreas } \\
\text { funcionais eram } 100 \% \\
\text { verticalizadas }\end{array}$ & $\begin{array}{l}\text { Relações com múltiplos fornece- } \\
\text { dores baseadas no baixo preço } \\
\text { e qualidade da matéria-prima }\end{array}$ \\
\hline E - Média & $\begin{array}{c}\text { CAD/CAM, } 11 \text { máquinas } \\
\text { automação fixa e } 7 \text { máquinas } \\
\text { com automação programável, } \\
\text { sendo } 2 \text { CNC. }\end{array}$ & $\begin{array}{l}\text { Produção } 100 \% \text { verticalizada; } \\
\text { atividades indiretas terceirizadas: } \\
\text { manutenção de máquinas, } \\
\text { informática, programa de higiene } \\
\text { e segurança no trabalho }\end{array}$ & $\begin{array}{l}\text { Relações com múltiplos } \\
\text { fornecedores baseadas } \\
\text { no baixo preço e qualidade da } \\
\text { matéria-prima }\end{array}$ \\
\hline F - Pequena & $\begin{array}{l}\text { CAD/CAM, } 5 \text { máquinas } \\
\text { automação fixa e } 1 \text { máquina } \\
\text { com automação programável }\end{array}$ & $\begin{array}{l}\text { 25\% da produção era } \\
\text { terceirizada; atividades indiretas } \\
\text { terceirizadas: manutenção } \\
\text { de máquinas, informática, } \\
\text { design, contabilidade } \\
\text { e depto. pessoal }\end{array}$ & $\begin{array}{c}\text { Relações com múltiplos } \\
\text { fornecedores baseadas no } \\
\text { baixo preço e qualidade da } \\
\text { matéria-prima }\end{array}$ \\
\hline G - Média & $\begin{array}{l}12 \text { máquinas com automação } \\
\text { fixa e } 4 \text { máquinas com } \\
\text { automação programável }\end{array}$ & $\begin{array}{l}\text { 2\% da produção era terceirizada, } \\
\text { porém as outras áreas funcionais } \\
\text { eram } 100 \% \text { verticalizadas }\end{array}$ & $\begin{array}{l}\text { Relações com múltiplos fornece- } \\
\text { dores baseadas no baixo preço } \\
\text { e qualidade da matéria-prima }\end{array}$ \\
\hline H - Micro & $\begin{array}{l}\text { CAD/CAM, } 7 \text { máquinas com } \\
\text { automação fixa, } 2 \text { máquinas } \\
\text { com automação programável } \\
\text { e ocorrência de estágio } \\
\text { manual em } 50 \% \text { do processo }\end{array}$ & $\begin{array}{l}\text { 2\% da produção era terceirizada; } \\
\text { atividades indiretas terceirizadas: } \\
\text { manutenção de máquinas; } \\
\text { informática; transporte; } \\
\text { programa de higiene e } \\
\text { segurança no trabalho }\end{array}$ & $\begin{array}{l}\text { Relações com múltiplos fornece- } \\
\text { dores baseadas no baixo preço e } \\
\text { qualidade da matéria-prima }\end{array}$ \\
\hline I - Micro & $\begin{array}{l}\text { CAD/CAM, } 5 \text { máquinas com } \\
\text { automação fixa, } 1 \text { máquina } \\
\text { com automação programável } \\
\text { e ocorrência de estágio } \\
\text { manual em } 50 \% \text { do processo }\end{array}$ & $\begin{array}{c}\text { Produção } 100 \% \text { verticalizada; } \\
\text { atividades indiretas terceirizadas: } \\
\text { informática, transporte } \\
\text { manutenção de máquinas, } \\
\text { programa de higiene e segurança } \\
\text { no trabalho }\end{array}$ & $\begin{array}{l}\text { Relações com múltiplos } \\
\text { fornecedores baseadas no } \\
\text { baixo preço e qualidade da } \\
\text { matéria-prima }\end{array}$ \\
\hline J - Pequena & $\begin{array}{l}\text { CAD/CAM, } 11 \text { máquinas com } \\
\text { automação fixa, } 3 \text { máquinas } \\
\text { com automação programável } \\
\text { e ocorrência de estágio } \\
\text { manual em } 50 \% \text { do processo }\end{array}$ & $\begin{array}{l}\text { 2\% da produção era terceirizada; } \\
\text { atividades indiretas terceirizadas: } \\
\text { contabilidade e departamento } \\
\text { pessoal, programa de higiene e } \\
\text { segurança no trabalho }\end{array}$ & $\begin{array}{l}\text { Relações com múltiplos } \\
\text { fornecedores baseadas no } \\
\text { baixo preço e qualidade da } \\
\text { matéria-prima }\end{array}$ \\
\hline K - Média & $\begin{array}{l}12 \text { máquinas com automação } \\
\text { fixa e } 4 \text { máquinas com } \\
\text { automação programável }\end{array}$ & $\begin{array}{l}\text { Produção } 100 \% \text { verticalizada; } \\
\text { atividades indiretas terceirizadas: } \\
\text { manutenção de máquinas e design }\end{array}$ & $\begin{array}{c}\text { Relações com múltiplos fornece- } \\
\text { dores baseadas no baixo preço } \\
\text { e qualidade da matéria-prima }\end{array}$ \\
\hline
\end{tabular}


tornos, entre outras. Já as máquinas de automação programável possuem mais de uma função e geralmente são programadas por um computador. Também, são preparadas fisicamente a cada mudança de lote de produtos, tais como: seccionadora e centro de usinagem (SILVA, 2003).

Observou-se que as empresas que possuíam estágio manual no processo produtivo eram empresas que tinham a linha de produto de móveis de assentos (sofás) e também, com exceção da empresa $\mathrm{B}$ (de médio porte), essas empresas eram de micro e pequeno porte $(\mathrm{C}, \mathrm{J}, \mathrm{H}$ e I). Entretanto, a maior parte das empresas de micro e pequeno porte também possuía máquinas com automação programável (A, D, F, H, I e J) (Tabela 3).

\section{A maior parte dos móveis era retilínea, A composta de móveis lisos, com desenhos simples e linhas retas.}

Poucas empresas repassavam parte de atividades e responsabilidade de produção para fornecedores. A terceirização nestas empresas era incipiente e estava distante dos conceitos de outsourcing, que se referem a fornecedores que desenvolvem e melhoram continuamente suas competências e a infra-estrutura para atender as necessidades de fabricação de seus clientes. A produção era em maior parte verticalizada, sendo que nas empresas $\mathrm{C}, \mathrm{G}$ e $\mathrm{H}$ havia apenas $2 \%$ de terceirização para detalhes nos móveis, constituídos por apliques de ferro e tubos de aço e, também, a empresa $\mathrm{F}$ terceirizava $25 \%$ da produção de cadeiras e a empresa $\mathrm{J}$ terceirizava $2 \%$ de estofamentos e tapeçaria (Tabela 4).

Notou-se que a maior parte da terceirização estava em atividades indiretas, tais como: informática, contabilidade, departamento de pessoal e transporte. Ainda, as empresas $\mathrm{D}$ e $\mathrm{G}$ não possuíam atividades indiretas terceirizadas (Tabela 4).

As relações com os fornecedores eram consideradas primárias, pois as exigências fundamentais definidas na compra de matéria-prima eram preço baixo, em primeiro lugar, e qualidade, em segundo. As empresas estabeleciam relações com múltiplos fornecedores e afirmavam que quase sempre existiam atrasos no prazo de entrega dos produtos e que alguns apresentavam defeitos (Tabela 4).

Cabe mencionar que as relações cooperativistas entre as empresas do pólo moveleiro de Votuporanga eram incipientes (SILVA, TORKOMIAN e BELHOT, 2002). A formação de cluster, ou seja, concentração geográfica de empresas de um mesmo setor industrial, pode trazer ganhos de eficiência coletiva, como a especialização entre produtores, o surgimento de fornecedores de máquinas e de matéria-prima e o surgimento de agentes que vendem para mercados distantes (HUMPHREY e SCHMITZ, 1998 apud AMATO, 2000).

Em se tratando do planejamento e controle da produção - PCP, a maior parte das empresas possuía resposta imediata da situação corrente de materiais em estoque; somente a empresa B dizia ser capaz de apontar a situação de seu estoque com índice de $75 \%$ de acerto. Também foi questionado o grau de conhecimento sobre o andamento das ordens de produção. As empresas D e E relataram conhecer o estágio das ordens em $50 \%$ das consultas, enquanto que nas empresas B, I e J esse índice subiu para $75 \%$. A maior parte (empresas $\mathrm{A}, \mathrm{C}, \mathrm{F}, \mathrm{G}, \mathrm{H}$ e $\mathrm{K}$ ) respondeu conhecer a situação das ordens com acerto de $100 \%$ (Tabela 4).

Normalmente, as empresas pesquisadas utilizavam tanto pacotes de escritório (word $e$ excel) quanto aplicativos personalizados para o planejamento e controle da produção. Somente a empresa A possuía sistema MRP II totalmente implantado e funcionando, enquanto as empresas $\mathrm{B}, \mathrm{C}, \mathrm{D}, \mathrm{E}, \mathrm{H}, \mathrm{J}$ e $\mathrm{K}$ o tinham implantado parcialmente. Já as empresas F, G, e I diziam ter conhecimento sobre o sistema, porém nada foi feito devido ao alto custo da implantação (Tabela 4).

Em relação às questões referentes à gestão da qualidade, somente a empresa A, que possuía a prioridade competitiva "qualidade", apontou o maior número de sistemas de controle voltados para esta prioridade. Já as empresas $\mathrm{G}$ e $\mathrm{K}$ apresentavam três ou mais sistemas, sendo que as prioridades competitivas adotadas foram a qualidade, seguida da flexibilidade e a qualidade seguida, de custo. Na maioria das vezes, o controle de qualidade era monitorado por meio da sensibilidade natural do operário na utilização de seus sentidos táteis, olfativos, auditivos e visuais (Tabela 5).

Todas as empresas pesquisadas indicaram que existia supervisão direta do processo de produção. Além disso, a coordenação do trabalho simples e informal na produção ocorria na maior parte dos processos de fabricação.

$\mathrm{Na}$ área de recursos humanos, os benefícios eram distribuídos da seguinte forma: assistência médicoodontológica (todas as empresas), convênio com farmácias (empresas A, B C, E, G e J), refeitório próprio (somente as empresas B, H, I e K), cesta básica (todas as empresas), premiação por produção (apenas as empresas B, F, J e K). 
Em se tratando de mão-de-obra qualificada para a indústria moveleira, algumas empresas subsidiavam treinamentos específicos, tais como: cursos técnicos no CEMAD (empresas A, E, F, H, I, J e K), grau tecnológico em móveis (empresas E, J e K) e cursos internos coordenados pelos fornecedores (empresas B, D, F, G e H). Entretanto, poucos funcionários tinham qualificações técnicas. Segundo a tabulação dos dados, apenas $9 \%$ dos funcionários freqüentavam cursos técnicos no CEMAD e 3,5\% possuíam instrução tecnológica em móveis.

\section{CONCLUSÕES}

O processo de formulação estratégica como descrito no referencial teórico não esteve presente nas empresas pesquisadas. Não existiam reuniões estratégicas que acompanhassem e avaliassem de forma rigorosa as decisões estruturais e infra-estruturais de produção. As reuniões normalmente tinham o objetivo de minimizar problemas imediatos. As decisões de médio e longo prazo eram baseadas na intuição e na experiência de "funcionários de confiança" do proprietário da empresa. Esses

Tabela 4: Linhas, classificação e estilos dos móveis; matéria-prima e comercialização.

\begin{tabular}{|c|c|c|c|c|}
\hline EMPRESA & $\begin{array}{c}\text { PROJETO DO } \\
\text { PRODUTO E DESIGN }\end{array}$ & LAYOUT & $\begin{array}{l}\text { PLANEJAMENTO E } \\
\text { CONTROLE DA } \\
\text { PRODUÇÃO - PCP }\end{array}$ & $\begin{array}{l}\text { INDIGADORES GERENCIAIS } \\
\text { UTILIZADOS PARA MONITORAR } \\
\text { A EFIIIÊNGIA DA PRODUĢĀOO }\end{array}$ \\
\hline A & $\begin{array}{l}\text { Desenvolvimento } \\
\text { interno }\end{array}$ & Em linha & $\begin{array}{l}\text { MRP II totalmente } \\
\text { implantado e } \\
\text { funcionando }\end{array}$ & $\begin{array}{l}\text { Produtividade / hora trabalhada; } \\
\text { índice de refugo e índice de } \\
\text { assistência técnica }\end{array}$ \\
\hline$B$ & $\begin{array}{l}\text { Desenvolvimento } \\
\text { interno }\end{array}$ & Em linha & $\begin{array}{l}\text { MRP ॥ em fase de } \\
\text { implantação }\end{array}$ & $\begin{array}{c}\text { Produtividade / hora trabalhada; } \\
\text { índice de devoluções e índice de } \\
\text { assistência técnica }\end{array}$ \\
\hline C & $\begin{array}{l}\text { Desenvolvimento } \\
\text { interno e definido pelo } \\
\text { consumidor }\end{array}$ & Em linha & $\begin{array}{l}\text { MRP ॥ em fase de } \\
\text { implantação }\end{array}$ & $\begin{array}{l}\text { Produtividade / hora trabalhada } \\
\text { e índice de assistência técnica }\end{array}$ \\
\hline D & $\begin{array}{l}\text { Contratação de } \\
\text { especialista }\end{array}$ & Em linha & $\begin{array}{l}\text { MRP \| em fase de } \\
\text { implantação }\end{array}$ & - \\
\hline $\mathrm{E}$ & $\begin{array}{l}\text { Desenvolvimento } \\
\text { interno e visitas a } \\
\text { feiras nacionais }\end{array}$ & Em linha & $\begin{array}{l}\text { MRP \| em fase de } \\
\text { implantação }\end{array}$ & - \\
\hline $\mathrm{F}$ & $\begin{array}{c}\text { Contratação de } \\
\text { especialista e visitas } \\
\text { em shoppings de móveis }\end{array}$ & Em linha & Manual & Produtividade / hora trabalhada \\
\hline G & $\begin{array}{l}\text { Desenvolvimento } \\
\text { interno }\end{array}$ & Em linha & Manual & Produtividade / hora trabalhada \\
\hline $\mathrm{H}$ & $\begin{array}{l}\text { Desenvolvimento } \\
\text { interno }\end{array}$ & Em linha & $\begin{array}{l}\text { MRP \| em fase de } \\
\text { implantação }\end{array}$ & Falta dos funcionários \\
\hline 1 & $\begin{array}{l}\text { Desenvolvimento } \\
\text { definido pelo consumidor } \\
\text { e contratação de } \\
\text { especialista }\end{array}$ & Em linha & Manual & $\begin{array}{l}\text { Índice de devoluções; índice } \\
\text { de assistência técnica e } \\
\text { faturamento por homem }\end{array}$ \\
\hline J & $\begin{array}{l}\text { Desenvolvimento } \\
\text { interno e visitas a } \\
\text { feiras nacionais }\end{array}$ & Em linha & $\begin{array}{l}\text { MRP \| em fase de } \\
\text { implantação }\end{array}$ & Produtividade / hora trabalhada \\
\hline K & $\begin{array}{l}\text { Desenvolvimento } \\
\text { interno e visitas a } \\
\text { feiras internacionais }\end{array}$ & Em linha & $\begin{array}{l}\text { MRP \| em fase de } \\
\text { implantação }\end{array}$ & $\begin{array}{l}\text { Produtividade / hora trabalhada } \\
\text { e índice de assistência técnica }\end{array}$ \\
\hline
\end{tabular}


eram responsáveis, na maioria das vezes, por atividades que envolviam a área financeira e de produção.

Assim, constatou-se que os conceitos de estratégia competitiva e de produção ainda eram poucos conhecidos. Acredita-se que essa limitação de ausência de conhecimento em razão de haver poucos estudos e literaturas na área de planejamento estratégico voltados para as pequenas e médias empresas. Conforme Cancelier (1998) e Menezes e Almeida (1997), as pequenas e médias apresentam algumas particularidades que interferem no processo de formulação do planejamento estratégico, como:

- A falta de cultura dos gestores em adotar a prática do planejamento estratégico de maneira mais formal;

- O imediatismo de resultados;

- A falta de pessoal qualificado para "pensar", trocar informações e experiências;

- Os recursos financeiros escassos para a contratação de consultores;

- A responsabilidade de tomada de decisão, tanto estratégica como operacional, está concentrada em um ou poucos indivíduos;

- A existência de uma série de funções operacionais exercidas pelo dirigente que o impedem de refletir sobre decisões estratégicas.

A seguir, são apresentadas as principais conclusões sobre a utilização das estratégias competitivas e a integração com as estratégias de produção. Também, são analisadas as prioridades competitivas e os fatores estruturais e infra-estruturais de produção.

A estratégia competitiva de menor custo foi predominante nas empresas pesquisadas, em função da comercialização em um mercado amplo com pouca ou nenhuma diferenciação. Não obstante, foi identificado um desalinhamento dessa estratégia com a prioridade competitiva de produção "custo", uma vez que a redução do custo de produção não era planejada a médio e longo prazo, mas simplesmente explorada para sanar problemas imediatos, aumentando os custos futuros. A seguir são apresentadas evidências desse desalinhamento, acompanhadas de observação dos autores (entre colchetes):

- A gestão de recursos humanos objetivava baixo custo na folha de pagamento, pois a maior parte dos funcionários tinha apenas escolaridade fundamental (1o grau). Além disso, das empresas que subsidiavam cursos técnicos aos funcionários, somente $9 \%$ deles se aprimoravam e 3,5\% possuíam instrução tecnológica.

[A não especialização de pessoal gera demora na produção, menor produtividade, baixo aproveitamento e utilização de recursos e conseqüentemente acarreta ausência de economia de escala.]

- A centralização na compra de matéria-prima pelo menor preço possível levava a relações com múltiplos fornecedores.

Tabela 5: Sistemas de controle de qualidade e as prioridades competitivas de produção.

\begin{tabular}{|c|c|c|c|c|c|c|c|c|c|c|c|}
\hline \multirow{2}{*}{$\begin{array}{l}\text { PRIORIDADES COMPETITIVAS } \\
\text { DE PRODUÇÃO E SISTEMAS DE } \\
\text { CONTROLE DE QUALIDADE }\end{array}$} & \multicolumn{11}{|c|}{ EMPRESAS } \\
\hline & A & B & c & D & E & $\mathbf{F}$ & G & $\mathrm{H}$ & I & J & K \\
\hline $\begin{array}{l}\text { Ordenação das duas primeiras prioridades } \\
\text { competitivas de produção }\end{array}$ & $Q^{1}, Q^{2}$ & $Q^{1}, C$ & $Q^{1}, C$ & $Q^{1}, C$ & $Q^{1}, Q^{2}$ & C, D & $Q^{1}, F$ & F, C & $Q^{1}, C$ & $C, Q^{1}$ & $Q^{1}, C$ \\
\hline Certificação ISO 9000 & $x$ & -- & -- & -- & -- & -- & -- & -- & -- & -- & -- \\
\hline Inspeção de recebimento de matéria-prima & $x$ & -- & -- & -- & -- & $x$ & $x$ & -- & $x$ & -- & $x$ \\
\hline Manutenção preventiva nas máquinas & $x$ & -- & -- & -- & -- & -- & -- & -- & -- & -- & $X$ \\
\hline $\begin{array}{l}\text { Documentação de especificação técnicas na } \\
\text { fábrica }\end{array}$ & $x$ & $x$ & -- & -- & -- & -- & $x$ & -- & -- & $x$ & $x$ \\
\hline $\begin{array}{l}\text { Desenhos de projeto que acompanham o } \\
\text { processo produtivo }\end{array}$ & $x$ & -- & -- & -- & -- & -- & $x$ & -- & -- & -- & -- \\
\hline $\begin{array}{l}\text { Controle através da sensibilidade natural do } \\
\text { operário na utilização dos seus sentidos } \\
\text { táteis, olfativos, auditivos e visuais }\end{array}$ & $x$ & $x$ & $x$ & $x$ & $x$ & $x$ & $x$ & $x$ & $x$ & $x$ & $x$ \\
\hline $\begin{array}{l}\text { Onde: C: custo; } \\
Q^{1} \text { : qualidade do produto final; } \\
Q^{2} \text { : qualidade conforme especificações técnicas; } \\
\text { F: flexibilidade; } \\
\text { D: desempenho ou rapidez na entrega. }\end{array}$ & & & & & & & & & & & \\
\hline
\end{tabular}


[Contrariamente, a prática de obtenção de matéria-prima a baixo custo, constatou-se que em uma das empresas pesquisadas freqüentemente havia atrasos no prazo de entrega e alguns produtos apresentavam defeitos, gerando aumento nos custos de produção].

- A maioria das empresas adotava o arranjo físico da produção em linha. Alguns produtos intermediários seguiam um fluxo de produção seqüencial, enquanto outros sofriam um fluxo de fabricação irregular. Existia um reaproveitamento significativo de restos de madeira que eram cortados, colados e prensados para serem reaproveitados antes de iniciar a fase de fabricação.

[Todavia, inexistiam indicadores ou aplicativos de computador que auxiliassem nas economias de recursos, tais como: CRAFT (Computerized Relative Allocation of Facilites), ALDEP (Automated Layout Design Program) e o CORELAP (Computerized Relationship Layout Planning). Constatou-se também a ausência de estudos dos benefícios ou desvantagens do reaproveitamento de restos de madeira e, além disso, não era mantido um controle secundário desse material; a falta de informação e de sistemas computadorizados causava desperdício de matéria-prima].

- As documentações e especificações técnicas de manuseio dos produtos na fábrica (quando existiam) eram muitas vezes imprecisas. Além disso, observou-se que em algumas empresas não utilizavam desenhos de projeto que acompanhassem o processo produtivo, o que resultava em processos de fabricação de produtos intermediários não-padronizados;

[A falta de uniformização do processo produtivo pode causar demora e falhas nos processos e na qualidade, aumentando-se os custos.]

Em se tratando da prioridade competitiva "qualidade do produto final", que foi reconhecida como um fator importante pelos empresários, constatou-se a inexistência da aplicação de programas que viabilizassem essa prioridade. Sabe-se que essa prioridade colabora para minimizar os custo de produção, já que com a padronização do trabalho pode haver rapidez na fabricação e aumento no volume dos produtos, resultando na economia de escala, como também, a adoção de sistemas de qualidade previne contra desperdícios ocasionados na produção. A seguir, são apresentadas as principais análises do desalinhamento relacionado à prioridade competitiva "qualidade do produto final":

- A inexistência de sistemas como: CEQ (controle estatístico da qualidade), TQM (sistema de gerenciamento de qualidade total), ISO 9000, programas de melhorias contínuas - Kaizen, manutenção preventiva, comprometimento e responsabilidade coletiva dos funcionários e os programas de garantia da qualidade. Além disso, o controle de qualidade era monitorado somente por meio da sensibilidade natural do operário (sentidos táteis, olfativos, auditivos e visuais).

\section{\gestão de recursos humanos ... objetivava custo na folha de pagamento... As políticas salariais mais adotadas eram o salário de mercado e a produtividade.}

[A falta de sistema de qualidade gera um trabalho que deve ser refeito, perda de produtos intermediários e, também, pode produzir um produto não uniforme. Por exemplo, os painéis de MDF (medium density fiber) e aglomerado eram geralmente cobertos com lâminas finas e colados em prensas automáticas de grande precisão. Todavia, a maior parte das lâminas tinha camadas fracas ou mal costuradas, sofrendo rasgos e empenamentos após o processo de prensagem. Não existiam normas técnicas que determinassem o controle de qualidade da produção de lâminas e que evitassem as compras com imperfeições. Como os defeitos nas lâminas ocorriam com frequêencia, utilizava-se uma massa de reparos na madeira para corrigílos, cuja aplicação era manual, resultando em gastos com materiais e tornando o processo de produção mais lento].

- A ocorrência de manutenção apenas emergencial e corretiva nas máquinas, o que ocasionava perdas de matéria-prima e de produto intermediário, interrupções e gargalos em alguns estágios de produção e conseqüientes atrasos dos produtos acabados.

[Sabe-se que quando ocorrem interrupções emergenciais geradas por problemas nas máquinas há perda de produtividade e redução de economia de escala, além de prejuízos com a matéria-prima e produtos intermediários rejeitados.]

Conclui-se que a prioridade competitiva qualidade mencionada pelos empresários referia-se apenas à utilização das matérias-prima que eram a madeira nativa (madeiras, nobres), a madeira reflorestada e o painel de MDF.

Contudo, vale ressaltar que para a fabricação de um móvel dito de qualidade, a madeira nativa necessita de secagem uniforme para não provocar defeitos durante o processo de produção. Alguns desses defeitos são: lasqueamentos, falhas nos processos de lixamento e conseqüentes branqueamentos das superfícies envernizadas. 
Uma solução para esse problema seria o uso de estufa de secagem ou a manutenção de um estoque maior de madeira para não causar demora no atendimento ao cliente. Das empresas pesquisadas, somente duas possuíam estufa de secagem e as restantes não obtinham capital de giro para sustentar o armazenamento da matéria-prima em grande quantidade.

Identificou-se, ainda, a falta de integração de sistemas computadorizados que auxiliam o planejamento e o controle da produção. Somente uma empresa possuía sistema MRP II totalmente implantado e funcionando, enquanto as outras o estavam implantando parcialmente ou utilizando sistemas manuais. Um problema detectado em uma das empresas, por exemplo, foi a digitação de nomenclaturas diferentes para um mesmo produto intermediário em razão do uso de softwares distintos, ocasionando confusão no controle de fechamento das ordens de produção.

Diante da análise dos dados levantados, conclui-se que inexistem técnicas e práticas precisas na gestão estratégica de produção que apóiem a estratégia competitiva de menor custo. Ocorriam unicamente tomadas de decisão que podiam reduzir o custo em curto prazo com a finalidade de se sustentar e sobreviver no momento presente, tais como:

- Políticas salariais primárias eram baseadas no salário de mercado e na produtividade. Os benefícios concedidos eram mínimos: premiação por produção, convênio médico-odontológico, cesta básica e convênio com farmácia. Apenas quatro empresas tinham refeitório próprio;

- Maior parte das máquinas era do tipo automação fixa, voltadas à alta taxa de produção e pouca flexibilidade, caracterizando um processo produtivo com pouca diversificação (móveis populares, de linhas retas e de baixo preço).

Não foram identificadas práticas das prioridades competitivas flexibilidade e desempenho nas entregas.

Contudo, vale dizer que alguns empresários da região de Votuporanga estavam preocupados com a competitividade do setor, pois estavam sofrendo reflexos da concorrência mundial e perdendo competitividade.

Algumas empresas já estavam se reestruturando. Por exemplo, a necessidade de reciclar o pessoal desqualificado fez com que fosse introduzido um curso superior de Tecnologia em Produção Moveleira no Centro Universitário de Votuporanga - CEUV e, também, fosse criado o Centro Tecnológico de Formação Profissional da Madeira e do Mobiliário - CEMAD. Ainda, iniciou-se, em setembro de 2003, um projeto de consórcio de exportação, chamado EXPAM - Exportadores Paulistas do Mobiliário, envolvendo 12 empresas da região (EXPAM, 2004). Tal projeto é subsidiado pelas empresas e conta com apoio do SEBRAE/SP, do SENAI e do CEMAD, podendo ser a base para uma reestruturação geral nessas empresas.

Finalmente, acredita-se que este estudo, apesar de exploratório, contribuiu para mostrar dados importantes sobre a indústria moveleira, como também promoveu um melhor discernimento dos conceitos de estratégia competitiva e de produção envolvidos no setor moveleiro de Votuporanga, tornando possíveis sugestões para trabalhos posteriores.

Ressalta-se que os empresários da região e os diretores do CEMAD são bem receptivos, sendo aceitável um maior estreitamento de parceria entre o CEMAD e a comunidade acadêmica. Identificam-se, nessa integração, alguns trabalhos que visem um maior alinhamento da estratégia de produção com a estratégia competitiva. Perspectivas para um desenvolvimento de pesquisas mais aprofundadas e estudos quantitativos em áreas específicas de produção e do setor moveleiro são sugeridos a seguir:

- Análise econômica para o aproveitamento de restos de madeira e implantação de sistema computadorizado para controle de estoque desse material;

- Criação de normas e controle de qualidade para o fornecimento de lâminas de madeira;

- Desenvolvimento de máquinas e técnicas alternativas para armazenamento da madeira nativa, já que o processo de secagem da madeira em estufa é oneroso para pequenas empresas;

- Estudo do conhecimento implícito dos operários para a criação e implantação da padronização de documentos técnicos e aperfeiçoamento do processo de fabricação conforme normas de qualidade voltadas para o setor moveleiro;

- Investigação de um sistema adequado de exaustor, pois nesse setor há um excesso de pó de madeira que gera problemas de qualidade no estágio de pintura e, também, na saúde dos operários;

- Análise de danos ao meio ambiente causados pelo excesso de pó de madeira.

Por fim, a realização de estudos, como os citados acima, possibilitará o confronto com diferentes pólos moveleiros mais fortalecidos e exportadores, como Bento Gonçalves - RS, Arapongas - PR, e São Bento do Sul - SC, que poderão contribuir para estimular um melhor desenvolvimento em regiões menos desenvolvidas. 
ABE, S.H.; PAVAM, J.L. Transformações da indústria moveleira de Votuporanga -SP.Gráfica universitária, 1999.

ABIMOVEL. Design na indústria brasileira de móveis. Disponível em $<$ http://www.abimovel.org.br/>. Acesso em: 05 jun. 2001.

ABIMOVEl. Panorama do setor moveleiro no Brasil. Disponível em: <http://www.abimovel.org.br/> Acesso em: 10 abr. 2002.

ABIMOVEL. Panorama do setor moveleiro no Brasil. Disponível em: <http://www.abimovel.org.br/> . Acesso em: 24 out. 2004

ALVES FILHO, A.G.; VANALLE, R.M Formulação e reformulação da estratégia de produção. In: CONGRESSO NACIONAL DE ENGENHARIA DE PRODUÇÃO, 18., 1998, Niterói. Anais ... Piracicaba: ABEPRO, 1998. 1 CD-ROM

AMATO, N.J. Redes de cooperação produtiva e clusters regionais: oportunidades para pequenas e médias empresas. São Paulo: Atlas, 2000.

BARROS NETO, J.B.; FENSTERSEIFER, J.E.; FORMOSO, C.T. O Diagnóstico estratégico da produção como instrumento de motivação para a formulação de estratégias de produção em pequenas empresas de construção e edificações. In: ENCONTRO NACIONAL DA ASSOCIAÇÃO NACIONAL DOS PROGRAMAS DE PÓS GRADUAÇÃO, 23., 1999, Foz do Iguaçu. Anais ... Rio de Janeiro: ANPAD, 1999; 1 CD-ROM.

CANCELLIER, E.L.P. de L. Formulação de estratégias em pequenas empresas: um estudo em pequenas empresas industriais da grande Florianópolis. Dissertação (Mestrado) - Universidade Federal de Santa Catarina, 1998.

COUTINHO, L. et al. Design na indústria brasileira de móveis. São Paulo: ABIMOVEL. (Estudos, 3), 2000.
EXPAM. Exportadores paulista do mobiliário. Disponível em: http:// www.expambrazil.com.br/historia.htm/ >. Acesso em: 24 out. 2004.

FINE, C.H.; HAX, A.C. Manufacturing strategy: a methodology and an illustration. Interfaces, v.15, p.28-46, Nov./Dec, 1985.

FREITAS, H. et al. O método de pesquisa survey. Revista de Administração (RAUSP), São Paulo, v.35, n.3, p.105112 , jul./set, 2000.

FUVEC. Fundação Votuporanguense de Educação e Cultura: banco de dados. Votuporanga, $27 \mathrm{dez} 2001$. Word for Windows 7.0.

GAZETA MERCANTIL.Jornal Gazeta Mercantil. Disponível em: <http:/ www.gazetamercantil.com.br/salavip/ >. Acesso em: 15 jun. 2001.

GORINI, A.P.F. A indústria de móveis no Brasil. São Paulo: ABIMÓVEL, 2000.

HAYES, R.H.; WHEELWRIGHT, S.C. Restoring our competitive edge: competing through manufacturing. New York: Free, 1984.

HILL, T. J. Manufacturing strategy keeping it relevant by adressing the needs of the market. Integrated Manufacturing Systems, Bradford, v.8/ 5, p.257-264, 1997.

HUMPHEREY, J., SCHMITZ, H. Trust and inter-firm relations in developing and transition economies. UK: IDS-Univ. of Sussex, 1998.

MARCONI, M.A. LAKATOS, E.M. Técnicas de pesquisa: planejamento e execução de pesquisas, amostragens e técnicas de pesquisa, elaboração, análise e interpretação de dados. $5^{a}$ ed. São Paulo: Atlas, 2002.

MENEZES, E.J.C.; ALMEIDA, M.I.R. Será possível as pequenas e médias empresas crescerem sem informações do ambiente? In: ENCONTRO NACIONAL
DOS PROGRAMAS DE PÓS-GRADUACÃO EM ADMINISTRACÃO ENANPAD, 17, 1997. Anais..., Gramado/Canela, Rio Grande do Sul/RS, 1997.

MILLS, J.; PLATTS, K.; GREGORY, M. A Framework for the design of manufacturing estratgy process: a contigency aprroach. International Journal of Operations \& Production Management, Bradford, v.15, n.4. p.17-49, 1995.

MINISTÉRIO DA CIÊNCIA E TECNOLOGIA (MCT). Financiadora de Estudos e Projeto. Estudo da competitividade da indústria brasileira: competitividade da indústria de móveis de madeira. Campinas: IE/UNICAMP, 1993.

MOREIRA, D.A. Administração da produção e operações. São Paulo: Pioneira Thomson Learning, 2001.

OLIVEIRA, D.P.R. de. Estratégia empresarial: uma abordagem empreendedora. 2. ed. São Paulo: Atlas, 1991.

PIRES, S.R.I. Integração do planejamento e controle da produção a uma estratégia de manufatura. Tese (Doutorado) - Escola de Engenharia de São Carlos, Universidade de São Paulo, São Carlos, 1994

PORTER, M.E. Competitive advantage: creating and sustaining superior perfomance. New York: Free, 1985.

SANTI, M.A. Contribuição aos estudos sobre as origens da produção seriada do mobiliário no Brasil: a experiência Móveis Cimo S/A. Dissertação (Mestrado) - Faculdade de Arquitetura e Urbanismo, Universidade de São Paulo, São Paulo, 2000.

SEBRAE - SERVICO BRASILEIRO DE APOIO ÀS MICRO E PEQUENAS EMPRESAS. Classificação das MPEs segundo o número de empregados. Disponível em: <http:/www.sebresp.com.br/ principal/>. Acesso em: 26 jun. 2005.
SILVA, E.M.; TORKOMIAN, A.L.V.; BELHOT, R.V. Um estudo exploratório sobre o cluster de indústria de móveis de Votuporanga - SP. In: CONGRESSO BRASILEIRO DE ENSINO DE ENGENHARIA COBENGE, 30, 2002. Anais... Piracicaba, São Paulo/SP, 2002.

SILVA, E. M. Alinhamento das estratégias competitivas com as estratégias de produção: estudo de casos no pólo moveleiro de Votuporanga - SP. 163 p. Dissertação (Mestrado) - Escola de Engenharia de São Carlos, Universidade de São Paulo, São Carlos, 2003

SKINNER, W. Manufacturing: the missing link in corporate strategy. Harvard Business Review, p.136-145, May-June, 1969.

SLACK, N. et al. Administração da produção. São Paulo: Atlas, 1999.

STIPP, M.S. Cluster industrial: o pólo moveleiro de Votuporanga-SP (19622001). Dissertação (Mestrado) - Universidade Estadual Paulista, Araraquara, 2002.

SWAMIDAS, P.M.; NEWELL, W.T Manufacturing strategy environmental and performace: a path analytic model Management Science, v. 133, n. 4, 1987.

VICKERY, S.K.; DROGE C.; MARKLAND R.E. Dimensions of manufacturing: strength in the furniture industry. Journal of Operations Management, v. 15 , p. 317-330, 1997.

VOSS, A.C. Alternative paradigms for manufacturing strategy. Internation Journal of Operations \& Production Management. v. 15, n. 4, 1995. p. 5-16, 1995.

WHEELWRIGHT, S.C.; HAYES, R.H Competing through manufacturing. Harvard Business Review, New York, v. 63, n. 1, p. 99-109, Jan./Feb, 1985.

YIN, R.K. Case study research: design and methods. 2. ed. Thousand Oaks, Sage, 1999

\section{- Sobre os autores}

\section{Eliciane Maria da Silva}

Universidade de São Paulo - Escola de Engenharia de São Carlos

Mestre e Doutoranda em Engenharia de Produção pela Escola de Engenharia de São Carlos da Universi-

dade de São Paulo

Endereço: Av. Trabalhador São-Carlense, 400 - C.P. 359 - CEP 13566-590 - SãoCarlos - SP

Tel.: (16) 3373-9385 / Fax: (16) 3373-9425

E-mail: eliciane@prod.eesc.usp.br

\section{Fernando César Almada Santos}

Universidade de São Paulo - Escola de Engenharia de São Carlos

Professor Doutor do Departamento de Engenharia de Produção

Endereço: Av. Trabalhador São-Carlense, 400 - C.P. 359 - CEP 13566-590 - São Carlos - SP

Tel.: (16) 3373-9385 / Fax: (16) 3373-9425

E-mail: almada@prod.eesc.usp.br 